\title{
Análise da transitividade e da construção identitária no gênero discussion: uma abordagem sistêmico-funcional
}

\section{Analysis of transitivity and identity construction in the discussion genre: a systemic-functional approach}

\author{
Heryzânya Alves Ramalho* \\ heryzanya@hotmail.com \\ Universidade Federal do Rio Grande do Norte \\ Jennifer Sarah Cooper \\ jennifersarahj@gmail.com \\ Universidade Federal do Rio Grande do Norte
}

RESUMO: Este artigo pretende analisar aspectos da transitividade em exemplares do gênero discussion numa perspectiva sistêmico-funcional (HALLIDAY, 1994; HALLIDAY, MATTHIESSEN, 2014; etc) com o intuito de observar de que forma as escolhas lexicogramaticais realizadas pelos autores dos textos auxiliam na construção identitária (IVANIČ,1998). Nesse intuito, foram investigados três textos que tratam da problemática do lixo residencial, os quais foram produzidos por alunos do curso de Conversação I em inglês do Instituto Ágora no segundo semestre de 2015 na UFRN. Os resultados da pesquisa apontam que os autores apresentaram o perfil do autor-cidadão que entende que o lixo é, também, responsabilidade de quem o produz. Para isso, os autores utilizaram, principalmente, os processos materiais no intuito de fundamentar argumentações e fazer recomendações. Eles também recorreram, especialmente, ao processo mental think para introduzir o seu posicionamento e o de outras pessoas em relação ao lixo.

PALAVRAS-CHAVE: Transitividade. Sistêmico-Funcional. Identidade. Gênero.

ABSTRACT: This article aims to analyze transitivity aspects in samples of the discussion genre from a systemic-functional perspective (HALLIDAY, 1994; HALLIDAY, MATTHIESSEN, 2014; etc) in order to observe how lexico-grammatical choices made by the authors of the texts help identity construction. To this end, we investigated three texts produced by students of the English Conversation I course from the Ágora Institute in the second semester of 2015 at UFRN concerning the problem of residential waste. The results of the research indicate that the authors presented the profile of the author-citizen who understands that garbage is also the responsibility of its producers. To achieve this aim, the authors mainly used the material processes to found arguments and make recommendations. They also used the mental process think especially to introduce their position and the position of others regarding the waste.

KEYWORDS: Transitivity. Systemic-Functional. Identity. Genre.

\footnotetext{
" Mestranda em Estudos da Linguagem pelo Programa de Pós-Graduação em Estudos da Linguagem da Universidade do Rio Grande do Norte

Doutora em Estudos da Linguagem pelo Programa de Pós-Graduação em Estudos da Linguagem da Universidade do Rio Grande do Norte e Professora Adjunta II no Departamento de Línguas e Literaturas Estrangeiras Modernas da mesma universidade.
} 


\section{Introdução}

Ter a identidade como objeto de estudo significa lidar com a incerteza, com a complexidade, pois, mesmo que o foco esteja apenas num único indivíduo, sabese que a identidade vai além dele mesmo: ela é construída nas relações diárias, nas experiências vividas de uma determinada sociedade e de uma determinada época. Isso significa que a identidade é produto de uma relação indissociável entre o indivíduo e aquilo que é externo a ele.

Vale ressaltar, também, que, pelo fato de não poder se dissociar do seu contexto cultural e histórico, o indivíduo deixa suas marcas em tudo aquilo que produz, sendo, assim, possível resgatar indícios que possibilitam suposições sobre a sua identidade. Nesse sentido, a linguagem, entendida pela linguística sistêmicofuncional (doravante LSF) como sistema de escolhas (HALLIDAY, 1994; HALLIDAY; MATTHIESSEN, 2014; IKEDA; VIAN JR., 2006), é um objeto caro para os estudos identitários, uma vez que as escolhas linguísticas feitas por um indivíduo na construção de sentidos revelam: de que maneira ele representa/ percebe o mundo externo e o seu próprio mundo interno (significado experiencial); de que forma ele estabelece relações com o(s) seu(s) interlocutor(es) em determinada situação (significado interpessoal); e como ele organiza aquilo que quer dizer (significado textual) (THOMPSON, 1996).

Nessa perspectiva, focamos, aqui, na identidade construída a partir do significado experiencial, pois a maneira com que o indivíduo escolhe representar o mundo revela determinado posicionamento quanto à representação criada, evidenciando, portanto, uma construção identitária. Para a análise dessas construções por meio do significado experiencial, utiliza-se o sistema de Transitividade (EGGINS, 1994; HALLIDAY, 1994; THOMPSON, 1996).

Tendo em vista essas considerações, o presente artigo tem como objetivo analisar de que forma a identidade é construída em textos do gênero discussion ${ }^{1}$ por meio de uma análise sistêmico-funcional de transitividade. Nesse intuito, o artigo está ancorado na teoria de Gênero e Registro (MARTIN; ROSE, 2008; ROSE; MARTIN, 2012), nos conceitos sobre identidade e discurso de Ivanič (1998) e, por

\footnotetext{
${ }^{1}$ Utilizamos o termo na língua inglesa por duas razões: 1) a teoria de Gênero \& Registro contempla este gênero discursivo em contextos de uso da língua inglesa; 2) os alunos participantes desta pesquisa se inserem no contexto de aprendizagem de língua inglesa e de seus respectivos gêneros discursivos.
} 
fim, nas concepções de língua e de transitividade da linguística sistêmico-funcional (doravante LSF) (EGGINS, 1994; HALLIDAY, 1994; HALLIDAY; MATTHIESSEN, 2014; THOMPSON, 1996).

Os textos do gênero discussion observados neste artigo foram retirados de uma parte dos dados coletados para a pesquisa de mestrado de uma das autoras que não foi utilizada na análise por não atender aos critérios propostos na dissertação.

Este estudo possui caráter qualiquantitativo (DÖRNYEI, 2007). A parte quantitativa da análise consiste na observação e quantificação dos padrões recorrentes de marcas linguísticas na escrita dos alunos que podem ajudar na identificação das identidades criadas. Por essa razão, analisamos o número de ocorrência dos processos e dos participantes nos textos a fim de estabelecer quais processos e participantes foram mais utilizados para, assim, entender o motivo dessas recorrências. No que se refere à parte qualitativa da análise, observamos as representações de mundo criadas em cada texto com o intuito de discorrer sobre como essas representações constroem uma identidade do autor na perspectiva de quem lê.

A pesquisa, também, se configura como um Estudo de Caso (MARTINS, 2008; NUNAN, 1992). Segundo os dois autores, esse tipo de pesquisa consiste no estudo de características tanto de um único indivíduo como de um grupo específico. Sendo assim, no caso desta pesquisa, observamos aspectos léxico-gramaticais de textos escritos produzidos por um grupo de três alunos provenientes de uma turma de Conversação I em inglês do Instituto Ágora da Universidade Federal do Rio Grande do Norte (Campus Natal) no início do segundo semestre de 2015. Os textos foram produzidos em sala de aula e foram coletados no mesmo dia sem mais intervenções. $^{2}$

No que se refere à organização do artigo, este se encontra dividido em duas partes. Na primeira parte, é apresentada a fundamentação teórica que se encontra subdividida em três seções: O gênero discussion, que apresenta a concepção de gênero à luz da LSF e introduz o gênero em análise; Identidade e Discurso, que trata da concepção de identidade abordada na pesquisa e de como ela é incorporada no

\footnotetext{
${ }^{2} \mathrm{O}$ ensino da produção escrita por meio de gêneros foi incentivado pela coordenadora de inglês do Ágora, baseando-se no programa Reading to Learn (ROSE, 2015). No entanto, a descrição completa dessa abordagem de ensino se encontra fora do escopo deste artigo.
} 
discurso e, por fim, Transitividade, que trata dos conceitos-chave da LSF nesse enfoque específico. A segunda parte, por sua vez, consiste na análise de dados que está dividida em três subseções referentes a cada texto analisado. Por fim, serão feitas observações sobre os resultados da pesquisa na Conclusão.

\section{Fundamentação teórica}

Nesta seção, apresentamos, primeiramente, o conceito de gênero numa perspectiva sistêmico-funcional para, então, tratarmos da discussion, que é o gênero analisado neste trabalho. Em seguida, abordamos a relação entre identidade e discurso na perspectiva de Ivanič (1998) para, finalmente, introduzirmos o sistema de Transitividade e seus conceitos-chave.

\subsection{0 gênero discussion}

Martin \& Rose (2008, p.6, tradução nossa) afirmam que "[...] gêneros são definidos como uma configuração recorrente de significados e que essas configurações recorrentes de significado possibilitam as práticas sociais de uma dada cultura" ${ }^{3} 4$. Seguindo essa linha de raciocínio, percebe-se que os gêneros não somente possibilitam as práticas sociais como também são estabelecidos por elas. Isto significa dizer que as práticas sociais são o motivo pelo qual os gêneros existem: elas são os acordos sociais numa determinada cultura que criam, remodelam e dão funcionalidade aos gêneros, fazendo, assim, com que eles circulem e que seus significados sejam resgatados pelos integrantes dessa cultura.

Rose \& Martin (2012) ainda apontam que os gêneros se desdobram em estágios e fases. Cada gênero possui estágios específicos (alguns obrigatórios, outros não) que possibilitam a progressão textual e que contribuem (cada um à sua maneira) para o propósito do gênero. Os estágios, ainda, podem ser divididos em fases que, juntas, cooperam com o propósito específico do estágio. Em relação a isso, os autores explicam que "cada estágio e fase de um gênero tem uma função

\footnotetext{
${ }^{3}$ Importa informar que todas as traduções de citações deste artigo foram feitas pelas autoras.

${ }^{4}$ No trecho original, em inglês: "[...] Genres are defined as a recurrent configuration of meanings and that these recurrent configurations of meaning enact the social practices of a given culture".
} 
especializada que contribui para o propósito social do gênero como um todo" (ROSE; MARTIN, 2012, p.54, tradução nossa).

No que se refere ao gênero discussion ${ }^{6}$, este pertence à família de gêneros argumentativos e tem como objetivo discutir sobre dois ou mais pontos de vista (ROSE, 2015). Os estágios e fases obrigatórios da discussion são apresentados no esquema a seguir (o símbolo ${ }^{\wedge}$ indica sequência dos estágios; o símbolo / indica uma fase ocorrendo dentro de um estágio; por fim, estágios iniciam com letra maiúscula enquanto fases iniciam com letra minúscula):

Problema ^ Lados/lado1/lado2 ^ Resolução

Primeiramente, para iniciar uma discussion, se faz necessário expor o problema que motivou o debate. Depois, são expostos os diferentes pontos de vista e seus respectivos argumentos em relação ao problema. Por fim, deve ser apresentada uma proposta de resolução do problema.

\subsection{Identidade e discurso}

Ivanič (1998) explica que identidade é a palavra que as pessoas geralmente utilizam para tratar de quem elas são. Contudo, é necessário acrescentar que, além de estar extremamente conectada à individualidade, a identidade é também uma produção social. Em relação a isso, a autora, baseando-se numa perspectiva sócioconstrucionista, esclarece que "[...] identidade não é socialmente determinada, mas socialmente construída" (IVANIČ, 1998, p. 12, tradução nossa) ${ }^{7}$. Isso significa que o indivíduo é reconhecido como parte integrante da sociedade e também como possível agente de mudança.

No referente à análise da identidade, Ivanič (1998, p.18, tradução nossa) afirma que 'o eu' '[...] não deveria ser concebido como algo a ser estudado isoladamente, mas como algo que se manifesta no discurso"8. $O$ foco do seu estudo, assim como o deste artigo, está na identidade manifestada no discurso escrito. A autora concebe discurso como sendo "[...] produzir e receber representações da

\footnotetext{
${ }^{5}$ No trecho original, em inglês: "Each stage and phase of a genre has a specialised function that contributes to the social purpose of the genre as a whole".

${ }^{6} \mathrm{O}$ termo não foi traduzido para o português pelo fato de que os gêneros a serem analisados estão em língua inglesa.

${ }^{7}$ No trecho original, em inglês: "[...] identity is not socially determined but socially constructed".

${ }^{8}$ No trecho original, em inglês: "[...] should not be conceived of as something to be studied in isolation, but as something which manifests itself in discourse".
} 
realidade culturalmente reconhecidas e ideologicamente formadas" (IVANIČ, 1998, p. 17, tradução nossa) $)^{9}$. Segundo ela, o discurso é o mecanismo mediador através do qual as pessoas passam a assumir identidades diferentes.

Essa visão corrobora com as premissas do modelo da língua pela perspectiva sistêmica: a relação dialética indissociável entre o contexto da cultura (o gênero), o contexto da situação (registro) e a linguagem (lexicogramática). Dessa maneira, quando o autor escreve em um idioma que não é o dele, como é o caso dos textos observados neste trabalho, tanto as escolhas linguísticas como os contextos de situação e de cultura tornam-se diferentes. Sendo assim, é possível que o autor construa, nesse texto, uma identidade que não corresponde à representação identitária que ele assumiria escrevendo na língua materna. Tais mudanças ocorrem pelo fato de que as configurações de significado entre uma cultura e outra tendem a ser diferentes.

Tendo em vista essas considerações, é importante relacionar a identidade a gênero. Para que os gêneros sejam reconhecidos e compartilhados por uma comunidade, eles precisam apresentar algumas características convencionadas socialmente. Dessa maneira, o autor de um texto, ao reconhecer tal necessidade, apresenta, automaticamente, traços de uma identidade que representa não somente a sua individualidade como também a força do social sob ele. Logo, o texto pode trazer várias máscaras sociais (ou identidades) que são assumidas pelo autor de acordo com o contexto situacional e cultural em que ele se encontra.

No que diz respeito às marcas linguísticas da identidade, Ivanič (1998) acredita que elas podem ser encontradas em diferentes níveis da língua, inclusive no sistema de transitividade, uma vez que as escolhas e arranjos feitos pelos usuários da língua são refletores de sua identidade. Se pensarmos nos participantes encontrados num texto, o uso frequente da primeira pessoa do singular, por exemplo, revela a necessidade do autor de mostrar quem é ou quem ele diz ser de forma explícita, o que não acontece se o autor apenas se utiliza de participantes abstratos para encobrir o seu 'eu' no discurso. Da mesma maneira, os outros elementos transitivos constituintes do texto fornecem detalhes sobre a imagem que o autor cria de si mesmo e de outros, seja de forma consciente ou não.

\footnotetext{
9 No trecho original, em inglês: "[...] producing and receiving culturally recognized, ideologically shaped representations of reality".
} 


\subsection{Transitividade}

Cunha \& Souza (2011, p.68) descrevem a transitividade, segundo a LSF, "[...] como a gramática da oração, como uma unidade estrutural que serve para expressar uma gama particular de significados ideacionais ou cognitivos". Por esse motivo, a transitividade não é uma propriedade apenas dos verbos, mas da oração como um todo e está presente nela em diversos níveis, diferentemente do conceito tradicional que se tinha de transitividade. No entanto, o cerne da oração ainda continua nos verbos, os quais são chamados de processos. Isso se dá pelo fato de que o tipo de processo determina os tipos de participantes na oração, sendo estes realizados por grupos nominais. Outro elemento possível na oração são as circunstâncias, que são realizadas por advérbios ou sintagmas adverbiais cuja função é acrescentar informações relacionadas ao processo e a seus participantes (CUNHA; SOUZA, 2011).

Halliday (1994) categoriza os processos em seis tipos: processos materiais, processos mentais, processos verbais, processos comportamentais, processos relacionais e processos existenciais.

Os processos materiais, segundo o autor, estão relacionados à "[...] experiência externa, [a]os processos do mundo exterior [...]"10 (HALLIDAY, 1994, p.107, tradução nossa); logo, os processos materiais são processos da ordem do fazer, do agir física e externamente. O participante principal e obrigatório nesse tipo de processo é o Ator, que é o praticante da ação. Por outro lado, os participantes opcionais nas orações materiais são: Meta, que é o participante que sofre a ação; Escopo, que não é afetado pelo processo, "[...] mas constrói o domínio no qual o processo acontece [...] ou constrói o processo em si [...]" ${ }^{11}$ (HALLIDAY; MATTHIESSEN, 2014, p.239, tradução nossa); Recipiente, que é aquele que recebe algo e Cliente, que é o participante para o qual serviços são prestados. Segue abaixo um exemplo de oração material:

\footnotetext{
${ }^{3}$ No trecho original, em inglês: "[...] outer experience, the processes of the external world [...]".

${ }^{11}$ No trecho original, em inglês: "[...] Rather it either (i) construes the domain over which the process takes place $[\ldots]$ or (ii) construes the process itself $[\ldots]$.
} 
Quadro 1. Exemplo de processo material

\begin{tabular}{|c|c|c|}
\hline The whole country & is paying & a heavy price \\
\hline Ator & Pr. Material & Escopo \\
\hline
\end{tabular}

Extraído de Halliday \& Matthiessen (2014, p.241)

No caso desse tipo de oração, sua alta recorrência em um gênero como a discussion geralmente demonstra uma tentativa de apresentar fatos que sirvam de base para as argumentações do autor. Cada processo material representa, portanto, uma ação que, para o autor, justifica certo tipo de pensamento, seja o dele ou de outrem.

Os processos mentais, segundo Eggins (1994, p.242, tradução nossa), são, por sua vez, "[..] processos que codificam significados do pensar ou do sentir [...]"12. Seu participante obrigatório é o Experienciador, que é aquele que pensa, sente ou percebe. Por essa razão, o Experienciador necessita ser um ser dotado de consciência (HALLIDAY; MATTHIESSEN, 2014). Outro participante recorrente nesse tipo de processo é o Fenômeno, que é aquilo que é pensado, sentido ou percebido. Segue abaixo um exemplo de oração mental:

Quadro 2. Exemplo de processo mental

\begin{tabular}{|c|c|c|}
\hline Mary & liked & the gift \\
\hline Experienciador & Pr. mental & Fenômeno \\
\hline
\end{tabular}

Extraído de Halliday \& Matthiessen (2014, p.248)

A utilização de processos mentais na discussion serve para expor os diferentes posicionamentos que geram o debate em questão. Por essa razão, há mais chances de que o autor se revele como participante na oração mental do que em qualquer outro tipo de oração.

No que diz respeito aos processos verbais, Thompson (1996, p.97, tradução nossa) os sintetiza como "[...] verbos do 'dizer"”'13. Os participantes envolvidos nesse tipo de processo são: Dizente, que é aquele que diz algo; Receptor, que é aquele

\footnotetext{
${ }^{12}$ No trecho original, em inglês: "[...] processes which encode meanings of thinking or feeling [...]".

${ }^{13}$ No trecho original, em inglês: "[...] verbs of 'saying'”. 
para quem o processo se direciona e Verbiagem, que é aquilo que é dito (CUNHA; SOUZA, 2011). Segue abaixo um exemplo de oração verbal:

Quadro 3. Exemplo de processo verbal

\begin{tabular}{|c|c|c|c|}
\hline You & ordered & a nice big pizza & for yourself \\
\hline Dizente & Pr. Verbal & Verbiagem & Receptor \\
\hline
\end{tabular}

Extraído de Halliday \& Matthiessen (2014, p.306)

A ocorrência de processos verbais em um texto argumentativo assinala a incorporação de outras vozes ao discurso, contribuindo, assim, para a compreensão da construção identitária social do autor. Isso significa que a adição dessas vozes no texto revela o contato prévio do autor com outros discursos relacionados à problemática abordada na discussion.

No referente aos processos comportamentais, Cunha \& Souza (2011, p.75) os definem como "[...] responsáveis pela construção de comportamentos humanos, incluindo atividades psicológicas como ouvir e assistir [...]". Seu participante obrigatório é o Comportante, aquele que realiza o processo. Outro participante que pode ocorrer nesse tipo de oração é o Behaviour ${ }^{14}$, cuja função é estender o processo. Segue abaixo um exemplo de oração comportamental:

\begin{tabular}{|} 
Quadro 4. Exemplo de processo comportamental \\
\begin{tabular}{|c|c|c|}
\hline We & can dance & without lobsters \\
\hline Comportante & Pr. Comportamental & Behaviour \\
\hline
\end{tabular} \\
\hline
\end{tabular}

Extraído de Halliday \& Matthiessen (2014, p.333)

Os processos comportamentais, no gênero discussion, geralmente servem à mesma função dos processos materiais: serem base para os argumentos construídos ao longo do texto.

Segundo Halliday \& Matthiessen (2014, p.259, tradução nossa), os processos relacionais "[...] servem para caracterizar e identificar" ${ }^{15}$. Tais processos podem, ainda, ser atributivos, com a função de atribuir algo a alguém ou a alguma

\footnotetext{
${ }^{14} \mathrm{O}$ termo ainda não havia sido traduzido para o português, de acordo com Cunha \& Souza (2011).

${ }^{15}$ No trecho original, em inglês: "[...] serve to characterize and to identify".
} 
coisa, ou identificadores, com a função de identificar algo ou alguém. No caso dos processos atributivos, os participantes são o Atributo, que é aquilo que é dado, e o Portador, que é aquele a quem algo é atribuído.

Quadro 5. Exemplo de processo relacional atributivo

\begin{tabular}{|c|c|c|}
\hline Sarah & Is & the wise one \\
\hline Portador & Pr. Rel. atributivo & Atributo \\
\hline
\end{tabular}

Extraído de Halliday \& Matthiessen (2014, p.299)

Em relação aos processos identificadores, os participantes existentes são a Característica, que é o elemento identificado, e o Valor, que é o elemento identificador (CUNHA; SOUZA, 2011).

Quadro 6. Exemplo de processo relacional identificador

\begin{tabular}{|c|c|c|}
\hline Tomorrow & is & the tenth \\
\hline Característica & Pr. Rel. identificador & Valor \\
\hline
\end{tabular}

Extraído de Halliday \& Matthiessen (2014, p.299)

Os processos relacionais são utilizados na discussion, principalmente, para fins de atribuições de valor e de organização das ideias do autor. Por essa razão, as orações relacionais são valiosas para a construção da identidade dele no texto, visto que indicam certa linha de raciocínio que pode, provavelmente, ser associada a um determinado grupo social.

Por fim, os processos existenciais, de acordo com Cunha \& Souza (2011, p.75), "[...] representam algo que existe ou acontece [...]".

Quadro 7. Exemplo de processo existencial

\begin{tabular}{|c|c|}
\hline There was & a storm \\
\hline Pr. existencial & Existente \\
\hline
\end{tabular}

Extraído de Halliday \& Matthiessen (2014, p.309) 
O participante que constrói a oração existencial é o Existente, como é possível observar no Quadro 7.

A utilização de processos existenciais no gênero em questão geralmente tem a finalidade de apresentar conceitos concebidos como fatos. Sendo assim, esse tipo de oração auxilia na formação da imagem do autor como defensor ou opositor de determinado pensamento.

\section{Análise}

Para uma análise mais detalhada, cada texto foi colocado numa subseção própria a fim de ser observado individualmente. Importa ressaltar que a informação em colchetes é referente aos estágios (inicial maiúscula) e fases (inicial minúscula) obrigatórios do gênero discussion. Os processos foram colocados em itálico para facilitar a sua localização e a dos seus participantes e circunstâncias. Outra informação importante é que o código que aparece antes da fonte do texto (A1T1, por exemplo) diz respeito ao aluno (A1) e ao texto que ele escreveu (T1), considerando que os textos analisados aqui fazem parte de um corpus maior.

Além disso, é necessário informar que os textos observados neste trabalho contêm desvios no que diz respeito à norma culta da língua inglesa. No entanto, as produções foram mantidas na sua forma original, dado que as inadequações também fazem parte da construção identitária no texto. Os textos originais em inglês ainda foram traduzidos em notas de rodapé com o intuito de facilitar a compreensão do leitor. Dessa maneira, os desvios originais foram traduzidos de forma equivalente em português.

Por último, vale salientar que todos os textos tratam da polêmica sobre o lixo residencial: se é um problema de todas as pessoas que produzem lixo ou se é um problema da prefeitura.

\subsection{Texto 1}

Segue, abaixo, o primeiro texto da análise:

Well, [Problema] The pollution is a topic much discussed currently at all 
levels of society. Generally people think that talking about environment is only adressing major issues. And it often seems that the problem is far from us. Saving the Amazon, for example. However, it's necessary to have a more responsible thinking about it. [lado 1] There are people who think that garbage your home is no longeran issue of it when it comes out of your home. It's a very problem.

[lado2] but there are people who make selective collection. [Resolução]l think we need public policies about it because many people do not know simple measures to preserve nature. ${ }^{16}$

[A1T1]. Fonte: Dados da pesquisa.

Em primeiro lugar, é preciso dizer que a palavra well não tem valor transitivo. Contudo, ela é importante para uma discussão sobre gênero e identidade, uma vez que assinala um traço bem mais informal do que o esperado numa discussion produzida em sala de aula. Em relação à identidade, percebe-se que o autor, ao usar tal expressão, dirige-se mais "amigavelmente" ao leitor, como se fora um conhecido.

Em segundo lugar, no que se refere à transitividade, existem dezenove (19) processos no texto, dentre eles: oito são relacionais atributivos, cinco são mentais, quatro são materiais e dois são existenciais.

O uso dos processos relacionais nos estágios do Problema e dos Lados se adequa ao propósito de ambos os estágios quando informações estão sendo apresentadas como em The pollution is a topic much discussed currently e it often seems that the problem is far from us. Contudo, o autor se utiliza dos processos relacionais para expor seus julgamentos ainda nesses estágios, como é possível observar nos trechos it's necessary to have a more responsible thinking about it e It's a very problem. A escolha por parte do autor de deixar marcada a sua opinião durante esses estágios e fases do texto constrói a identidade de alguém que possui uma opinião formada sobre o assunto e prefere não se esconder no texto, mas que assume uma maneira mais informal e menos estratégica de mostrar seu posicionamento, pois não segue a proposta de cada estágio.

\footnotetext{
${ }^{16}$ No trecho original, em inglês: "Bem, [Problema] A poluição é um tópico muito discutido atualmente em todos os níveis da sociedade. Geralmente as pessoas pensam que falar sobre ambiente é apenas tratar problemas maiores. E frequentemente parece que o problema está distante de nós. Salvar a Amazônia, por exemplo. No entanto, é necessário ter um pensamento mais responsável em relação a isso. [lado1] Existem pessoas que acham que lixo sua casa não é mais problema disso quando sai da sua casa. É um muito problema. [lado2] mas existem pessoas que fazem coleta seletiva. [Resolução] Eu acho que nós precisamos de políticas públicas sobre isso porque muitas pessoas não conhecem medidas simples para preservar a natureza".
} 
Dos cinco processos mentais, três se referem ao processo think, enquanto os outros são need e do not know. O uso do processo think no lado1 acompanhado do Experienciador people sugere uma suposição sem fundamentação de algumas pessoas, mostrando, assim, a vulnerabilidade dos argumentos desse lado. Ainda, a oração é seguida pelo julgamento It's a very problem. Dessa maneira, o autor se apresenta abertamente como adverso às pessoas que acham que o lixo doméstico, depois de colocado para fora, não é mais problema delas. No entanto, o autor se utiliza da mesma escolha lexicogramatical para mostrar seu posicionamento na Resolução, em I think we need public policies about it. Embora a oração com think possa ser compreendida apenas como achismo por parte do leitor, a opção pelo pronome na primeira pessoa do singular mostra necessidade do autor de assumir a responsabilidade pelo que foi dito e evidencia o seu ponto de vista.

Em relação aos processos materiais, vale destacar o uso de make seguido do escopo selective collection no lado2. Enquanto as outras pessoas acham coisas (think), ou seja, não realizam nenhuma ação concreta, existem pessoas que fazem algo concreto como a coleta seletiva. Logo, a escolha do processo material sobre o processo mental dá mais credibilidade ao lado2, que é o lado compartilhado pelo autor.

No caso dos processos existenciais, eles são utilizados para mostrar dois tipos de pessoas distintas: as que não veem o lixo depois de jogado fora como problema delas e as que fazem coleta seletiva.

Outra observação importante é que, embora o autor demonstre o seu posicionamento em todo o texto, assumindo brevemente, na Resolução, sua opinião em relação ao assunto ao utilizar o participante $I$, ele se reinsere num grupo, por meio do participante we, a fim de evocar o senso de comunidade face às medidas que devem ser tomadas para solucionar o problema.

\subsection{Texto 2}

Segue, abaixo, o segundo texto da análise:

[Problema] Waste pollution is one of the biggest problems of the cities in these days. When the population in the cities grows, the volume of waste also grows; and there isn't more space on the city to put this 
waste. Public policies are good, we have good lows, but people doesn't know them and, either doesn't matter where it's waste go on. [lado 1?] For me, the more important discuss is about what people think whose waste is. Everyone produce waste, but think that responsibility about its destination is only by government. It's wrong! The responsibility of each one begins when they bay the products. Each one can choose if buy a recycle product or not.

[lado 2?] Garbage pollution affects the quality of water and also of the air and soil. The impacts in the people's health are huge. Besides, impacts like in the landscape of the cities, reduce the tourism. Finally, changing climate also is affected by the garbage pollution.

[Resolução] So, residential waste is a individual problem. When people doesn't think about the waste that each one produce; when they think that the responsibility is by the city, it is a great problem. If people use the 3Rs, reduce, reuse, recycle, I think it will be better. ${ }^{17}$

[A7T1]. Fonte: Dados da pesquisa.

Após a leitura do texto, percebe-se que os dois parágrafos do meio não tratam de lados distintos, mas de duas questões referentes ao problema do lixo: a responsabilidade do lixo doméstico e os impactos da poluição pelo lixo. Dessa forma, o texto não somente se distancia do propósito da discussion como também se aproxima de outro gênero na família de gêneros argumentativos: a Exposition, que trata da exposição de apenas um ponto de vista.

O texto possui um total de trinta e quatro processos: catorze são materiais, doze são relacionais, sete são mentais e um é existencial. A recorrência maior de processos materiais aponta para acontecimentos relacionados ao problema do lixo, principalmente para as consequências e efeitos da poluição. O autor se utiliza tanto de participantes abstratos (como impacts, residential waste, pollution) para tratar desses acontecimentos como de participantes humanos (everyone, each one, people) para mostrar as atitudes das pessoas em relação a esse problema. A variedade e o uso recorrente de processos materiais, como grows, produce, affects,

\footnotetext{
${ }^{17}$ Nossa tradução do texto: "[Problema] A poluição pelo lixo é um dos maiores problemas das cidades atualmente. Quando a população nas cidades aumenta, o volume do lixo também aumenta; e não há mais espaço na cidade para colocar este lixo. Políticas públicas são boas, nós temos boas baixas, mas as pessoas não as conhecem e, ou não importa onde é lixo continua. [lado1?] Para mim, o discutir mais importante é sobre o que as pessoas pensam de quem o lixo é. Todo mundo produz lixo, mas pensa que responsabilidade sobre sua destinação é somente por governo. Está errado! A responsabilidade de cada um começa quando eles baía os produtos. Cada um pode escolher se compra um produto de reciclar ou não. [lado2?] A poluição pelo lixo afeta a qualidade da água e também do ar e do solo. Os impactos na saúde das pessoas são enormes. Além disso, impactos como na paisagem das cidades, reduzem o turismo. Finalmente, a mudança de clima também é afetada pela poluição causada pelo lixo. [Resolução] Então, o lixo residencial é uma problema individual. Quando as pessoas não pensam sobre o lixo que cada um produz; quando eles pensam que a responsabilidade é pela cidade, é um grande problema. Se as pessoas usam os 3R's, reduzir, reusar, reciclar, eu acho que vai ser melhor".
} 
por exemplo, assim como de diferentes participantes, criam a imagem de alguém que está a par do assunto, uma vez que apresenta vários "fatos" referentes à problemática. A variedade na escolha dos processos também ajuda a criar a imagem de alguém que tem um vocabulário relativamente bom em inglês. Tal imagem faz com que se pense no autor como alguém que domina o assunto e que, consequentemente, transmite confiança.

No caso dos processos relacionais, nove são atributivos e três são identificadores. Enquanto os processos atributivos são usados para mostrar opiniões envolvendo o assunto, os identificadores apresentam opiniões de maneira mais enfática, como, por exemplo, em Waste pollution is one of the biggest problems of the cities in these days. O Atributo one of the biggest problems pretende chamar a atenção, pois promete tratar de algo significativo. Na frase for me, the more important discuss is about what people think whose waste is, o autor se apresenta, com o uso do pronome me, no estágio em que deveriam ser apresentados os lados da discussão. Sendo assim, o autor se utiliza dos processos relacionais atributivos para trazer a questão que acha mais importante na discussão sobre o lixo.

Em relação aos processos mentais, o autor faz uso recorrente de think. Da mesma forma que os outros processos mentais, o autor utiliza o processo para apresentar os pensamentos e o desconhecimento das pessoas em relação ao problema do lixo. Porém, assim como o autor do primeiro texto, o autor do segundo texto se utiliza do mesmo processo e se revela como experienciador para expressar sua opinião no final da Resolução: If people use the $3 R s$, reduce, reuse, recycle, I think it will be better. Percebe-se, portanto, mais uma vez, a necessidade de se manifestar no texto e deixar claro o seu ponto de vista.

\subsection{Texto 3}

Segue, abaixo, o terceiro e último texto da análise:

[Problema]Pollution is a concerning problem around the world, because we have many ways to contaminate the environment. Some of them are dangerous, not to be immediately injured, but they have a long time consequences. The residential waste is one. We have daily thrown many things in the air, waters and earth, without noticing or not. 
[lado 1] Some people think that residential waste is not an individual problem and consider governments and politicians are guilt, because they can't do anything, as citizens, about this by themselves. In general, they reclaim about the waste in the street, beaches, parks and think that their responsibilities end when they pay fees or bills.

[lado2? resolução?] Residential waste becomes an individual problem when we don't put the waste in a correct destiny, when we contribute to dirty areas and places. Then, we have to do our part to live in the world where all the people have rights and obligations. If each one of us act with conscience, we have a better place to live.

[Resolução] Residential waste begins as my individual problem and continues as a society's problem or a city's problem. People should have environmental education to know how to do with their waste and collect them in a good way. This is a cycle and depends on a several steps, not me not you exclusively ([A3T1] Fonte: Dados da pesquisa) ${ }^{18}$.

Após uma leitura do texto, é importante observar, primeiramente, que o autor apresenta o lado2 da discussão de uma forma diferente: ele assume esse lado ao mesmo tempo em que expõe argumentos e inicia sua resolução. O autor passa a assumir uma identidade coletiva constante representada pelos participantes we, our e us na fase que seria o lado2, mas que funciona também como parte da resolução. A evocação de uma identidade coletiva pelo uso desses pronomes é um apelo para que o leitor se sinta parte do grupo e, consequentemente, tenda a concordar com a resolução proposta.

O texto possui um total de trinta e cinco processos: dezesseis são materiais, treze são relacionais, cinco são mentais e um é verbal.

O autor se utiliza de diferentes processos materiais, como contaminate, have thrown e collect, por exemplo, aliados a participantes humanos, como we e people, a fim de expor as ações das pessoas (incluindo o autor) em relação ao lixo e de

\footnotetext{
${ }^{18}$ Nossa tradução do texto: "[Problema] A poluição é um problema preocupante ao redor do mundo, porque nós temos muitas maneiras de contaminar o meio ambiente. Algumas delas são perigosas, não para ser imediatamente prejudicado, mas elas têm umas consequências a longo tempo. O lixo residencial é uma. Nós temos jogado muitas coisas no ar, águas e terra diariamente, sem perceber ou não. [lado1] Algumas pessoas acham que o lixo residencial não é um problema individual e consideram governos e políticos são culpa, porque eles não podem fazer nada, como cidadãos, sobre isso por eles mesmos. Em geral, eles reivindicam sobre o lixo na rua, praias, parques e acham que suas responsabilidades terminam quando eles pagam taxas ou contas. [lado?resolução?] $O$ lixo residencial se torna um problema individual quando não colocamos o lixo num destino correto, quando contribuímos para áreas e lugares sujos. Então, nós temos que fazer a nossa parte para viver no mundo em que todas as pessoas têm direitos e deveres. Se cada um de nós agirmos com consciência, nós temos um lugar melhor para viver. [Resolução] O lixo residencial começa como meu problema individual e continua como um problema da sociedade ou um problema da cidade. As pessoas deveriam ter educação ambiental para saber como fazer com seu lixo e coletá-los de uma boa maneira. Isto é um ciclo e depende de vários passos, não eu não você exclusivamente".
} 
apresentar as atitudes que deveriam ser tomadas em relação ao problema. $\mathrm{Na}$ oração we don't put the waste in a correct destiny, por exemplo, o autor assume uma identidade coletiva, talvez se escondendo nela em detrimento da má ação que é não colocar o lixo no destino correto e/ou talvez se assumindo como parte do grupo a fim de apresentar a ação como atitude generalizada entre as pessoas. O autor apenas se mostra como indivíduo no texto na Resolução ao utilizar as palavras my e me, embora o faça num sentido mais amplo, de modo que o leitor também possa se reconhecer nos pronomes.

Dentre os processos relacionais, doze são atributivos e um é identificador. Os processos atributivos são usados para apresentar informações e fazer julgamentos. O único processo identificador da discussion, por sua vez, é utilizado para identificar o lixo residencial como um problema com consequências a longo prazo (The residential waste is one, com one se referindo a ways to contaminate). Dessa maneira, o autor se apresenta como uma pessoa que procura alertar outros sobre o perigo do lixo residencial ao mesmo tempo em que propõe soluções, como em People should have environmental education, por exemplo.

Os processos mentais nesse texto são quase todos utilizados para expressar os posicionamentos das pessoas de quem o autor discorda. O processo think é usado duas vezes com esse propósito, diferentemente dos outros dois textos em que os autores se utilizam desse processo para se referirem tanto à opinião alheia quanto a deles próprios.

Por fim, a ocorrência do processo verbal traz uma questão significante: pelo contexto, percebe-se que o autor usa o processo reclaim não no sentido em inglês, mas no da sua língua materna. Essa inadequação é interessante do ponto de vista identitário e cultural pelo fato de que os leitores que compartilham a mesma língua materna e possuem conhecimento mais avançado do inglês reconhecerão de imediato a alteração, assim como também serão atentados para o fato de que o autor é um brasileiro que está aprendendo inglês.

\section{Conclusão}

A análise dos três exemplares do gênero discussion aliada a questões de identidade revelou características importantes sobre as máscaras sociais que os autores adquirem por meio de suas escolhas no nível lexicogramatical. A utilização 
de determinados processos e participantes em estágios ou fases específicas do texto tem influência no modo como o leitor enxerga o seu interlocutor e no modo como avalia os argumentos da discussão.

Em relação aos processos materiais analisados nos três textos, pôde-se perceber que eles foram utilizados para mostrar ações relacionadas à questão do lixo, o que ajuda a criar a imagem de um autor que está a par do assunto e sugere modificações nas atitudes das pessoas em relação a isso. A predominância dos processos materiais dentre os exemplares analisados do gênero discussion ocorre pelo fato de que, ao apresentar ações relacionadas ao problema do lixo, os autores podem, a partir disso, basear suas opiniões e avaliações, o que é fundamental para o gênero em questão.

No caso dos processos relacionais, eles foram usados para dar informações e expor julgamentos, o que cria uma identidade do autor como alguém que revela a situação e que não está omisso em relação ao problema do lixo.

Por sua vez, os processos mentais foram utilizados para mostrar os pensamentos e impressões tanto das pessoas que são criticadas quanto dos autores em geral. $\mathrm{O}$ uso recorrente de think, particularmente, se deu para mostrar pensamentos contrários. Entretanto, nos dois primeiros textos, os autores utilizaram o mesmo processo para mostrar seu pensamento.

Os processos existenciais, por outro lado, foram usados para mostrar a existência de pessoas com posicionamentos contrários aos do autor e também para apresentar fatos que servem como argumentos para a proposta do autor.

No caso do único processo verbal da análise, este se deu de forma incorreta, uma vez que o autor utilizou o falso cognato reclaim no sentido de reclamar. No entanto, essa inadequação é importante no que se refere à identidade cultural, pois é possível perceber, a partir disso, que o autor é brasileiro e que o processo utilizado por ele é uma marca da interferência da língua materna na aprendizagem de língua inglesa.

No referente aos participantes utilizados, vale ressaltar o uso recorrente dos pronomes ligados à primeira pessoa do plural, we, como uma maneira de trazer à tona uma identidade coletiva igualitária, na qual todas as pessoas têm a mesma responsabilidade e sofrerão as mesmas consequências em relação ao problema do lixo. 
O uso dos pronomes relacionados à primeira pessoa do singular, $I$, também foi recorrente. Nos dois primeiros textos, o autor apresenta a sua resolução pessoal utilizando esse pronome. Porém, no último texto, o autor utiliza os pronomes me e my de forma diferenciada, de maneira que o leitor possa entender que esses participantes se referem a ele também.

Em suma, ambos os autores concordaram com a ideia de que o lixo é um problema de cada cidadão e que políticas públicas deveriam ser implantadas com o intuito de conscientizar a população e, consequentemente, diminuir a poluição causada pelo lixo. Nesse sentido, a identidade comum a todos os textos é de que os autores são cidadãos preocupados com a questão da poluição causada pelo lixo e que, por isso, sugerem que cada pessoa assuma a responsabilidade dos resíduos produzidos em casa. Esse tipo de pensamento em prol do meio ambiente vem sendo cada vez mais disseminado nas últimas décadas, indicando, portanto, que os autores dos textos são defensores da proposta contemporânea de sustentabilidade.

\section{Referências}

CUNHA, M. A. F.; SOUZA, M. M. Transitividade e seus contextos de uso. São Paulo: Cortez, 2011.

DÖRNYEI, Z. Research methods in Applied Linguistics. Oxford: Oxford University Press, 2007.

EGGINS, S. An Introduction to Systemic Functional Linguistics. London e New York: Continuum, 1994.

HALLIDAY, M. A. K. An Introduction to Functional Grammar. 2. ed. London: Edward Arnold, 1994.

HALLIDAY, M. A. K.; MATTHIESSEN, M. I. M. Halliday's introduction to Functional Grammar. 4. ed. New York: Routledge, 2014.

IKEDA, S. N.; VIAN JR., O. A Análise do discurso pela perspectiva sistêmicofuncional. In: LEFFA, V.J. (Org.). Pesquisa em Linguística Aplicada: temas e métodos. Pelotas: Educat, 2006. p. 37-75.

IVANIČ, R. Writing and identity: The discoursal construction of identity in academic writing. Amsterdam/Philadelphia: John Benjamins Publishing Company, 1998.

MARTIN, J. R.; ROSE, D. Genre relations: mapping culture. London: Equinox, 2008. 
MARTINS, G. A. Estudo de caso: uma estratégia de pesquisa. 2. ed. São Paulo: Editora Atlas, 2008.

NUNAN, D. Research methods in language learning. Cambridge: Cambridge University Press, 1992.

ROSE, D. Reading to learn: accelerating learning and closing the gap. Sydney: UTS, 2015.

ROSE, D.; MARTIN, J.R. Learning to write, reading to learn: genre, knowledge and pedagogy in the Sydney School. London: Equinox, 2012.

THOMPSON, G. Introducing Functional Grammar. London: Arnold, 1996. 